\title{
Redosing antibiotics during cardiopulmonary bypass: The time is now
}

\author{
Heather Lander, MD, and Simon C. Body, MBChB, MPH
}

\footnotetext{
From the Department of Anesthesiology, Perioperative and Pain Medicine, Brigham and Women's Hospital/Harvard Medical School, Boston, Mass.

Disclosures: Authors have nothing to disclose with regard to commercial support.

Received for publication May 2, 2016; accepted for publication May 2, 2016; available ahead of print May 25 , 2016.

Address for reprints: Simon C. Body, MBChB, MPH, Department of Anesthesiology, Perioperative and Pain Medicine, Brigham and Women's Hospital, 75 Francis St, Boston, MA 02115 (E-mail: sbody@partners.org).

J Thorac Cardiovasc Surg 2016;152:611-2

$0022-5223 / \$ 36.00$

Copyright (C) 2016 by The American Association for Thoracic Surgery

http://dx.doi.org/10.1016/j.jtcvs.2016.05.009
}

Surgical site infections (SSIs) in postoperative cardiac surgical patients are devastating complications associated with increased morbidity, mortality, and cost. In a time in which outcome measures have substantial implications for reimbursement and overall consumer ratings, considerable amounts of attention and effort are paid to preventive measures. Protocol-driven perioperative antibiotic prophylaxis and stringent aseptic technique have been successful in minimizing the occurrence of SSIs; however, patients who undergo cardiopulmonary bypass (CPB) represent a unique patient population who still acquire SSIs.

Current Society of Thoracic Surgeons prophylactic antibiotic guidelines from 2007 recommend administration of a $\beta$-lactam antibiotic for standard surgical prophylaxis, with the addition of a glycopeptide in high-risk patient populations to cover methicillin-resistant Staphylococcus aureus. ${ }^{1}$ These guidelines make specific recommendations for initial dosing; however, there remains uncertainty regarding appropriate redosing strategies.

It is well established that CPB increases pharmacokinetic volume of distribution as a result of hemodilution, altered protein binding, tissue distribution, and sequestration in the CPB circuit. ${ }^{2}$ This effect is especially marked for hydrophilic drugs such as vancomycin and first-generation cephalosporins, including cefazolin.

In this issue of the Journal, Lanckohr and colleagues ${ }^{3}$ from Muenster, Germany, report the pharmacokinetics of cefazolin during cardiac surgery with CPB and the minimum inhibitory concentrations of organisms present on the patients' skin. Starting with an initial Society of Thoracic Surgeons-recommended dose of $2 \mathrm{~g}$ of cefazolin, they then added an additional 2-gram dose of cefazolin after initiation of CPB. After initiation of CPB but before administration of the second dose of cefazolin, cefazolin concentration fell by approximately $40 \%$. In this small study, despite initiation of CPB, cefazolin levels were still greater than $8 \mathrm{mg} / \mathrm{L}$ in all patients, their patients.

\section{References}

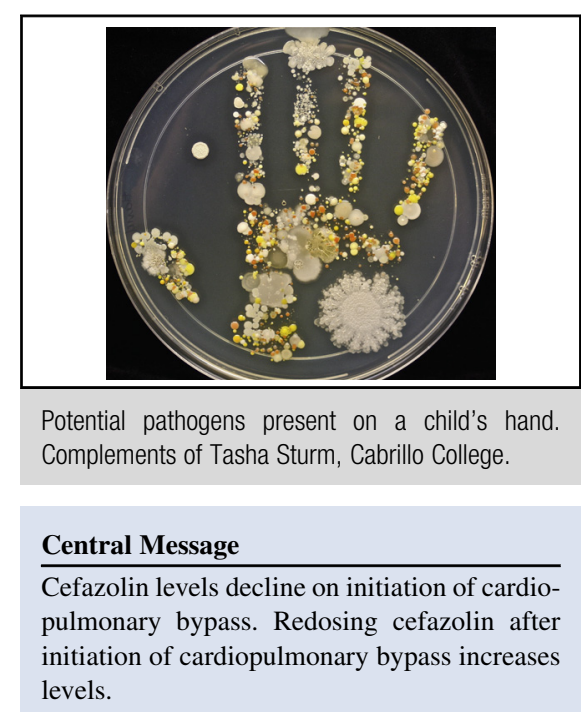

See Article page 603.

above the minimum inhibitory concentration of observed skin organisms. Redosing cefazolin increased median cefazolin levels to those seen after the first dose. Further, although they observed that more than $90 \%$ of pathogens on the patients' skin were sensitive to cefazolin, there is a lack of information regarding the sensitivities of the remaining pathogens and whether they would be covered by the serum levels of cefazolin observed in

An important limitation of this study is the lack of a control group that did not receive an additional dose of cefazolin on initiation of CPB. We therefore cannot be certain that cefazolin levels greater than $8 \mathrm{mg} / \mathrm{L}$ would not similarly be achieved until the next routine 3- or 4hour dose of cefazolin. Is this a necessary study before adoption of additional cefazolin dosing and incorporation into revised Society of Thoracic Surgeons antibiotic guidelines? We think that it is not. Overall, readministration of cefazolin after CPB initiation is a low-risk, lowcost, and potentially high-benefit clinical decision in light of the grave consequences of development of SSIs. Strong consideration should be given to adopting earlier intraoperative redosing strategies for antibiotic prophylaxis in patients undergoing CPB.

1. Engelman R, Shahian D, Shemin R, Guy TS, Bratzler D, Edwards F, et al. Workforce on Evidence-Based Medicine, Society of Thoracic Surgeons. The Society of 
Thoracic Surgeons practice guideline series: antibiotic prophylaxis in cardiac surgery, part II: antibiotic choice. Ann Thorac Surg. 2007;83:1569-76.

2. Mets B. The pharmacokinetics of anesthetic drugs and adjuvants during cardiopulmonary bypass. Acta Anaesthesiol Scand. 2000;44:261-73.
3. Lanckohr C, Horn D, Voeller S, Hempel G, Fobker M, Welp H, et al. Pharmacokinetics and microbiological appropriateness of cefazolin for perioperative antibiotic prophylaxis in elective cardiac surgery. J Thorac Cardiovasc Surg. 2016;152: 603-10. 